in vivo $34: 2067-2071(2020)$

doi:10.21873/invivo.12009

\title{
Hepatic Xanthogranuloma that Originated from a Liver Cyst and Mimicked a Malignant Tumor
}

\author{
ERI ODA ${ }^{1}$, TORU BEPPU ${ }^{1}$, KOICHI KINOSHITA ${ }^{1}$, KENSUKE YAMAMURA $^{1}$, \\ NOBUTAKA SATO ${ }^{1}$, HIDEAKI YUKI $^{2}$, SUGURU CHIYONAGA ${ }^{3}$, \\ TOSHIHIKO MOTOHARA ${ }^{3}$, YOSHIHIKO KOMOHARA ${ }^{4}$ and SHINICHI AKAHOSHI ${ }^{1}$ \\ ${ }^{1}$ Department of Surgery, Yamaga City Medical Center, Kumamoto, Japan; \\ ${ }^{2}$ Department of Radiology, Yamaga City Medical Center, Kumamoto, Japan; \\ ${ }^{3}$ Department of Gastroenterology, Yamaga City Medical Center, Kumamoto, Japan; \\ ${ }^{4}$ Department of Cell Pathology, Graduate School of Medicine, Kumamoto University, Kumamoto, Japan
}

\begin{abstract}
Background/Aim: Hepatic xanthogranuloma is a very rale disease and formation process is unknown. Case Report: A 69-year-old woman previously diagnosed as simple liver cyst. Two years before, a 36-mm liver cyst was found in segment 5, while one year later, the hemorrhagic cyst was $40 \mathrm{~mm}$ in diameter and a thin septum had formed. The most recent T1-weighted magnetic resonance imaging (MRI) showed a regular 21-mm hepatic mass with a hyperintense 11-mm center and a hypointense periphery. Peripheral enhancement was seen on gadolinium enhanced MRI. Hepatobiliary cystadenoma or cystadenocarcinoma was suspected because of wall thickness and slight enhancement. Microscopic examination following laparoscopic partial liver resection revealed fibroblasts, dense collagen fibers, and a double layer of hemosiderinladen as well as foamy macrophages attached to the fibrous capsule. Conclusion: The patient was diagnosed with a hepatic xanthogranuloma that originated from a hemorrhagic liver cyst. Intracystic hemorrhage may be one of the reasons for hepatic xanthogranuloma formation.
\end{abstract}

Juvenile xanthogranuloma is a non-Langerhans cell form of histiocytosis and commonly manifests as cutaneous mass, subcutaneous or deep soft tissues mass, extracutaneous nonsoft tissue lesion, and visceral-systemic lesions (1, 2). Among such juvenile xanthogranulomas, visceral-systemic

This article is freely accessible online.

Correspondence to: Toru Beppu, Department of Surgery, Yamaga City Medical Center, 511, Yamaga, Kumamoto, 861-0593, Japan. Tel: +81 968442185, Fax: +81 968442420, e-mail: tbeppu@yamaga-mc.jp

Key Words: Hepatic xanthogranuloma, simple liver cyst, intracystic hemorrhage. lesions has rarely reported; only 5\% (1). The etiology of juvenile xanthogranuloma is not fully understood. A genetic background has been suggested given the multiple sites of occurrence; however, familial cases have not been reported. In adult cases, xanthogranulomatous cholecystitis mimicking gallbladder cancer is sometimes described $(3,4)$. To our knowledge, few cases of hepatic xanthogranuloma has been reported $(5,6)$. It is difficult to differentiate from hepatic malignancies by diagnostic images other than histological examination. On microscopic examination, xanthogranuloma is consisted of foamy macrophages and chronic inflammatory cells, including lymphocytes and plasma cells $(5,6)$.

In our patient, progressive changes exposed through diagnostic imaging studies clearly showed the transformation of a simple liver cyst into a xanthogranuloma that mimicked a malignant tumor.

\section{Case Report}

A simple 36-mm diameter liver cyst in segment 5 was found in this 69 -year-old woman 2 years before. At the time, the cyst appeared as a homogeneous hypointense signal on T1weighted magnetic resonance imaging (MRI) (Figure 1A) and a clear homogeneous high-intensity signal on T2weighted images (Figure 1B). Neither cyst wall thickening nor intracystic nodules were observed. One year later, MRI revealed a slight enlargement of the cyst to $40 \mathrm{~mm}$ in diameter and formation of a thin septum. The intracystic signal had changed from hypointense to hyperintense on T1weighted images, probably as a result of intracystic hemorrhage (Figure 1C). No change other than cyst size and septum formation was observed in T2-weighted images (Figure 1D). The most recent MRI showed a regular hepatic mass with a much smaller diameter of $21 \mathrm{~mm}$, an $11-\mathrm{mm}$ hyperintense center, and a hypointense periphery with T1- 

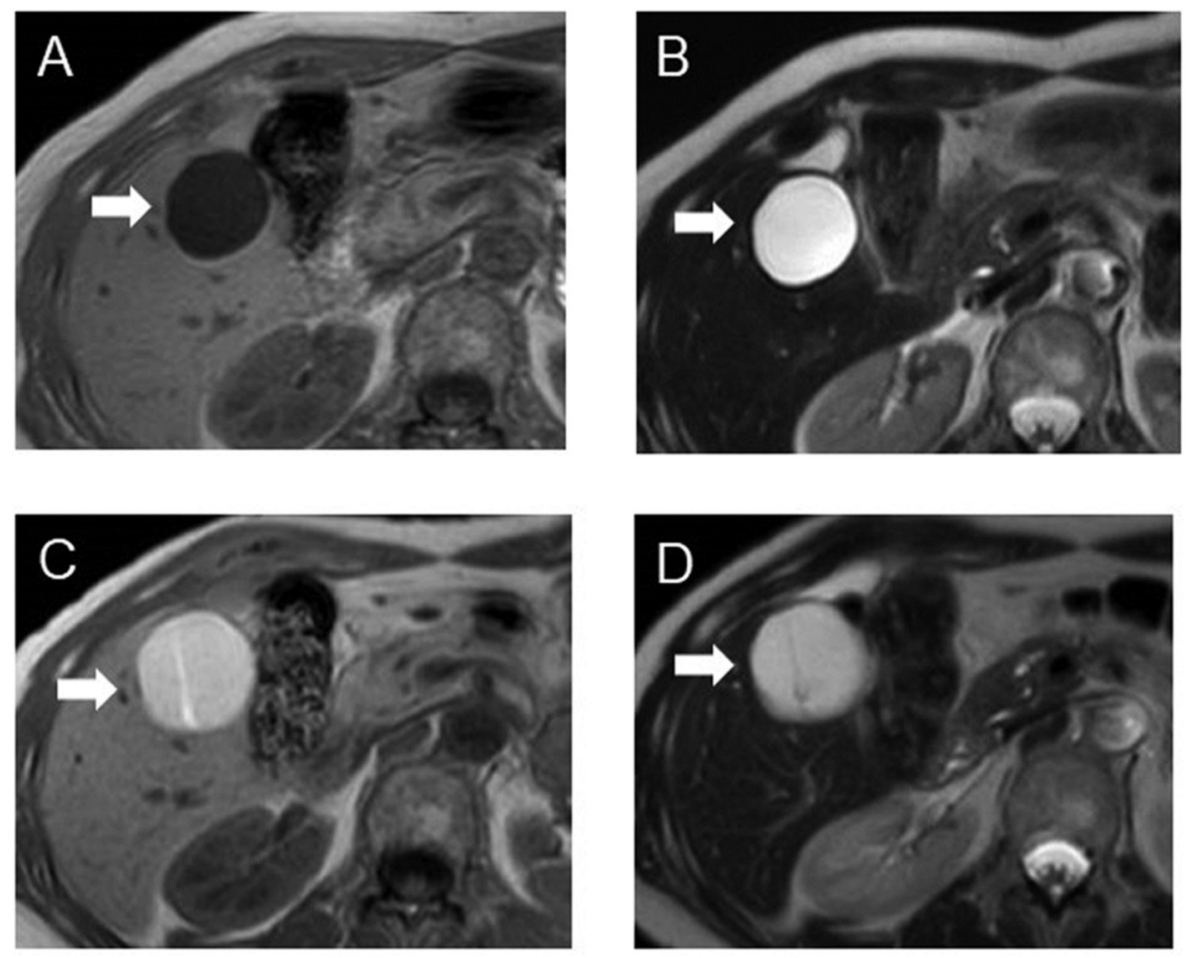

Figure 1.T1-and T2-weighted MRIs $2(A, B)$ and 1 year $(C, D)$ before hepatic xanthogranuloma formation show the change from a simple hepatic cyst to a complex cyst with evidence of intracystic hemorrhage (arrow).
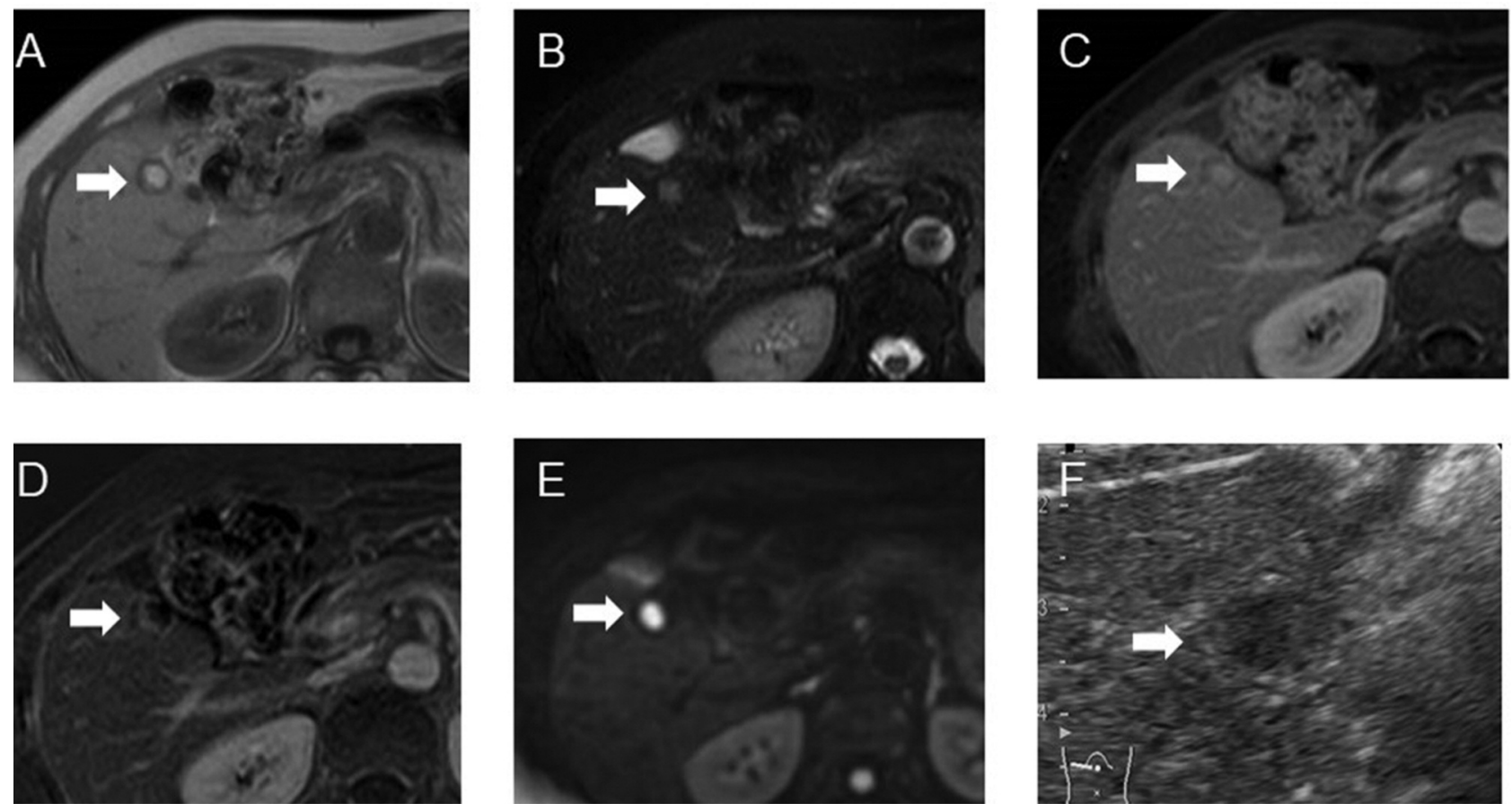

Figure 2. Images diagnostic of hepatic xanthogranuloma. (A) T1-weighted MRI, (B) T2-weighted MRI, (C) T1-weighted MR image with gadolinium enhancement, $(D)$ postcontrast enhanced subtraction image, $(E)$ diffusion-weighted image, and $(F)$ ultrasound image. The hepatic xanthogranuloma is indicated by arrows. 
weighting (Figure 2A). T2-weighting revealed high intensity in the central area and iso- to low-intensity in the periphery (Figure 2B). Peripheral enhancement was seen using gadolinium contrast MRI (Figure 2C), and the subtraction image clearly showed peripheral enhancement and absence of enhancement within the central area (Figure 2D). Diffusion-weighted MRI showed restricted diffusion with high signal intensity on b800 image sequences (Figure 2E). Ultrasound found an isoechoic mass that included a central hypoechoic structure without posterior acoustic enhancement (Figure 2F).

Serological tests for hepatitis B and C virus were both negative. Liver function tests, C-reactive protein concentration, and the white blood cell count were within the normal ranges. Serum carcinoembryonic antigen (CEA), carbohydrate antigen (CA) 19-9, and $\alpha$-fetoprotein were all below normal limits (Table I). The patient remained asymptomatic throughout.

The change in tumor appearance and wall thickness with slight enhancement led to an initial diagnosis of hepatobiliary cystadenoma or cystadenocarcinoma that had developed from a complex liver cyst. The patient consented to a laparoscopic partial resection of liver segment 5 and cholecystectomy. Gross pathology confirmed a $13-\mathrm{mm}$ central cystic lesion encapsulated by thick white fibrous tissue and including yellow and brown areas (Figure 3A). Microscopic evaluation revealed fibroblasts, dense collagen fibers, and two layers of hemosiderin-laden and foamy macrophages attached to the fibrous capsule (Figure 3B). Evidence of an old hemorrhage was observed in the central zone of the cystic lesion (Figure 1F). Neither multinucleate giant cells nor evidence of fibroblast or myofibroblast proliferation were observed. The histological findings were consistent with hepatic xanthogranuloma originating from a simple liver cyst.

The patient was discharged on postoperative day 11 with no morbidity. Her general condition was good with no relapse of disease more than 1 year after surgery.

\section{Discussion}

This patient was being routinely monitored after the discovery of an asymptomatic solitary hepatic cyst. One year after the first visit, the cyst had increased in volume with changes of intensity on T1-weighted MRI that were suggestive of intracystic hemorrhage. Intracystic septa had also developed. Simple hepatic cysts usually lack septa, while these are more often seen in neoplastic cysts (7). A year later, a regular hepatic mass was seen on MRI. It had decreased in size, and the T1-weighted image had a hyperintense center and a hypointense periphery. Slight homogenous early enhancement without delayed washout in the periphery was seen on contrast-enhanced MRI. Simple
Table I. Patient laboratory values on admission.

\begin{tabular}{lcclcc}
\hline T-protein & 7.0 & $\mathrm{~g} / \mathrm{dl}$ & AFP & 2.3 & $\mathrm{ng} / \mathrm{ml}$ \\
Albumin & 4.6 & $\mathrm{~g} / \mathrm{dl}$ & CEA & 1.1 & $\mathrm{ng} / \mathrm{ml}$ \\
T-bilirubin & 0.8 & $\mathrm{mg} / \mathrm{dl}$ & CA19-9 & 28.0 & $\mathrm{U} / \mathrm{ml}$ \\
D-bilirubin & 0.2 & $\mathrm{mg} / \mathrm{dl}$ & & & \\
ALT & 27 & $\mathrm{U} / \mathrm{l}$ & HBs-Ag & $(-)$ & \\
AST & 18 & $\mathrm{U} / 1$ & HCV-Ab & $(-)$ & \\
LDH & 202 & $\mathrm{U} / 1$ & & & \\
ALP & 150 & $\mathrm{U} / 1$ & White blood cell & 4.7 & $\times 10^{3} / \mu \mathrm{l}$ \\
$\gamma$-GTP & 21 & $\mathrm{U} / 1$ & Neutrophil & 60.1 & $\%$ \\
Cholinesterase & 316 & $\mathrm{U} / 1$ & Lymphocytes & 33.1 & $\%$ \\
Ammonia & 48 & $\mu \mathrm{g} / \mathrm{dl}$ & Monotypes & 5.1 & $\%$ \\
& & & Eosinophil & 1.1 & $\%$ \\
BUN & 21.3 & $\mathrm{mg} / \mathrm{dl}$ & Basophil & 0.6 & $\%$ \\
Creatinine & 0.8 & $\mathrm{mg} / \mathrm{dl}$ & & & \\
& & & Red blood cell & 4.09 & $\times 10^{6} / \mu \mathrm{l}$ \\
CRP & 0.02 & $\mathrm{mg} / \mathrm{dl}$ & Hemoglobin & 13.6 & $\mathrm{~g} / \mathrm{dl}$ \\
SAA & 4.4 & $\mu \mathrm{gg} / \mathrm{ml}$ & Platelet & 225 & $\times 10^{3} / \mu \mathrm{ll}$ \\
& & & & & \\
FBS & 95 & $\mathrm{mg} / \mathrm{dl}$ & PT activity & 95.5 & $\%$ \\
Hb A1c & 5.6 & $\%$ & APTT & 25.4 & $\mathrm{~seconds}$ \\
& & & ICG R15 & 8.0 & $\%$ \\
\hline & & & & &
\end{tabular}

ALT: Alanine transaminase; AST: aspartate aminotransferase; $\gamma$-GTP: $\gamma$-glutamyl transpeptidase; LDH: lactate dehydrogenase; ALP: alkaline phosphatase; BUN: blood urea nitrogen; CRP: C-reactive protein; SAA: serum amyloid A; FBS: Fasting blood glucose; Hb: hemoglobin; AFP: alpha-fetoprotein; CEA: carcinoembryonic antigen; CA19-9: carbohydrate antigen 19-9; HBs-Ag: Hepatitis B virus surface antigen; HCV-Ab: hepatitis C virus antibody; PT: prothrombin time; APTT: activated partial thromboplastin time; ICGR15: indocyanine green retention rate at $15 \mathrm{~min}$.

liver cysts that have neoplastic potential and progress to form hepatic cystadenoma or cystadenocarcinoma often have an enhanced solid component (8). The final diagnosis was made using histological evaluation of tissue obtained during partial hepatic resection.

It is difficult to differentiate hepatic xanthogranuloma from malignant neoplasms by preoperative imaging $(5,6)$. Abdominal ultrasound showed a solid heterogeneous hepatic mass with a hypoechoic rim in this patient. Previous findings in patients with hepatic xanthogranulomas have included an irregular hypodense mass without significant contrast enhancement or with mild peripheral arterial enhancement without contrast washout in the late phase of contrastenhanced computed tomography. A diffuse hypermetabolic mass that mimics a malignant tumor may be found on ${ }^{18} \mathrm{~F}$ fluorodeoxyglucose positron emission tomography (9). Additionally, chronic expanding hematomas show significantly high ${ }^{18} \mathrm{~F}$-fluorodeoxyglucose uptake (10). The MRI findings in a previously reported case of juvenile hepatic xanthogranuloma were similar to those in this adult patient. T1-weighted images showed areas of signal intensity similar to or less than that of the surrounding parenchyma. The lesion had slight gadolinium enhancement in the 


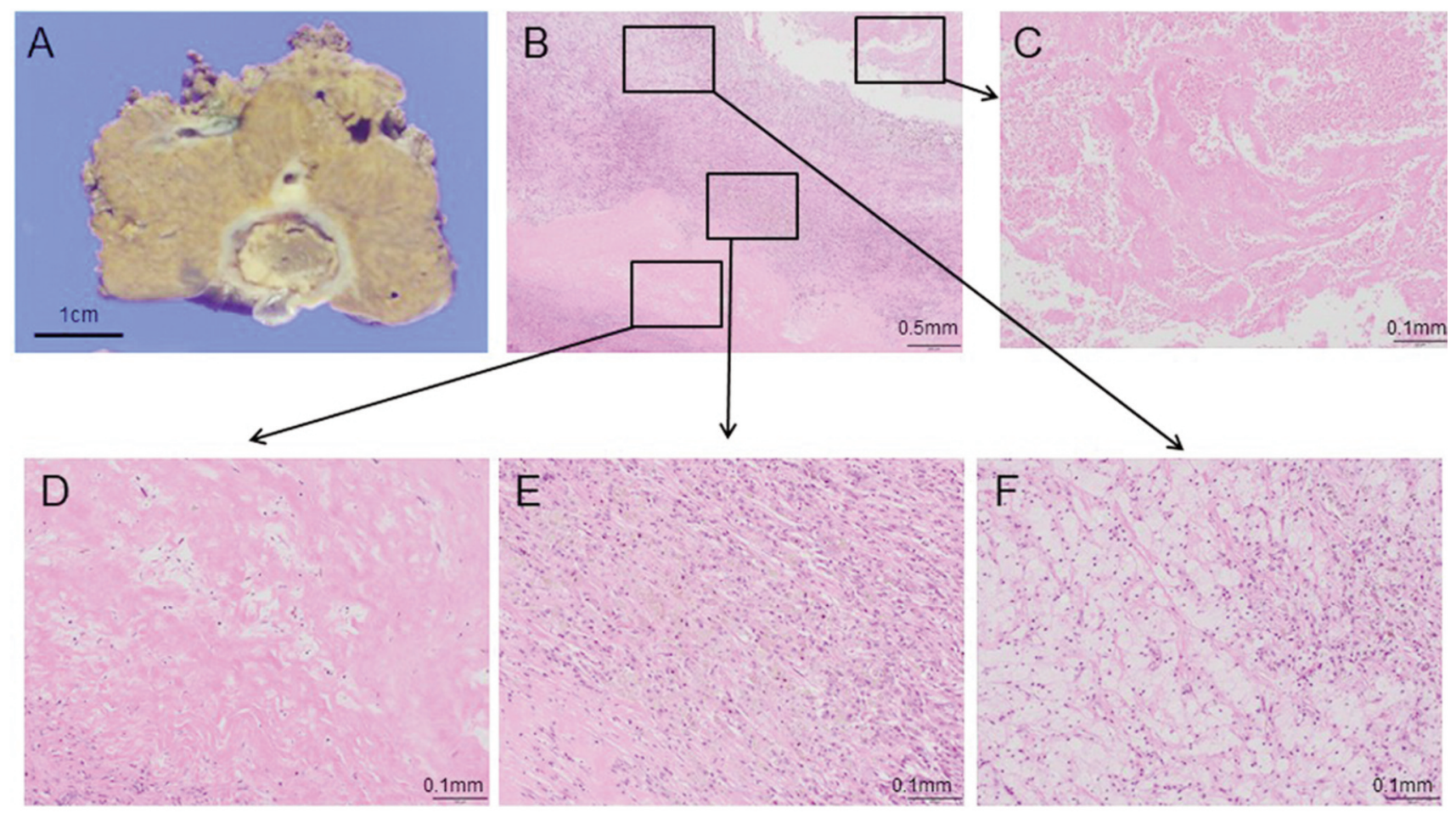

Figure 3. Macroscopic and microscopic findings show the cut surface of a resected tissue specimen. (A) Shows histopathological findings at low magnification $(\times 12.5)$ and $(B)$ high magnification $(\times 60)$. Inserts in $(B)$ show a previous hemorrhage $(C)$, fibrous tissue $(D)$, hemosiderin-rich macrophages $(E)$, and foamy macrophages $(F)$.

periphery, and T2-weighted imaging showed a lesion with increased signal intensity in the center (5).

Fine needle aspiration cytology is useful for diagnosing cystic lesions but cytology is often negative in patients with cystadenocarcinoma (11-13). Elevation of CEA and CA19-9 concentrations in cyst fluid has high specificity and sensitivity to distinguish between hepatic cancers and simple cysts. Frozen tissue sections obtained by percutaneous transhepatic biopsy or laparoscopic fenestration are useful for the diagnosis of cystic liver lesions, but risk the seeding of tumor cells from suspected malignant cystic tumors (1113). Surgical exploration and resection should be considered to rule out malignancy. Laparoscopic liver resection was chosen for this patient as it is a standard procedure with high safety and low invasiveness $(14,15)$.

The diagnosis of xanthogranuloma can be confirmed by pathological evaluation of resected tissue. Macroscopically, xanthogranuloma appears as a soft yellow nodule. The microscopic anatomy includes a stroma with dense collagenous fibers, small arteries, and no bile ducts (1-6). Foamy macrophages and other cells, characteristic of chronic inflammation, including lymphocytes and plasma cells, are present. Some cases of hepatic xanthogranuloma have been previously identified, and IgG4-related inflammatory pseudotumors (IPTs) with a histology resembling xanthogranuloma have been reported in the liver $(16,17)$. It is, thus, possible that some cases of xanthogranuloma have been reported as IPTs. IPTs are characterized by a mixed population of inflammatory cells and fibroblast and myofibroblast proliferation $(16,17)$. As no evidence of fibroblast or myofibroblast proliferation was seen in this tumor, we believe xanthogranuloma was the appropriate diagnosis and that this originated from a simple liver cyst during pathological tissue remodeling following hemorrhage and inflammation. A destructive granuloma similar to xanthogranuloma derived from a simple liver cyst has previously been reported (18). Laparoscopic partial liver resection is preferable to biopsy or cytology for suspicious hepatic cystic tumors and close followup is recommended for patients who present with diagnostic imaging findings typical of nonmalignant tumors.

\section{Conflicts of Interest}

The Authors declare no conflicts of interest.

\section{Authors' Contributions}

EO and TB identified the concept and wrote the draft of the paper; KK, KY, NS, HY, SC, TM, and SA actually treated the patient and collected data; YK examined pathological findings. 


\section{Acknowledgements}

The Authors wish to thank their colleagues and staffs in Yamaga City Medical Center, for their kind cooperation and support.

\section{References}

1 Dehner LP: Juvenile xanthogranuloma in the first decades of life. A clinicopathologic study of 174 cases with cutaneous an extracutaneous manifestations. Am J Surg Pathol 27(5): 579-593. 2003. PMID: 12717244. DOI: 10.1097/00000478-20030500000003

2 Sangüeza OP, Salmon JK, White CR Jr and Beckstead JH: Juvenile xanthogranuloma: a clinical, histopathologic and immunohistochemical study. J Cutan Pathol 22(4): 327-335, 1995. PMID: 7499572. DOI: 10.1111/j.1600-0560.1995.tb01415.x

3 Hale MD, Roberts KJ, Hodson J, Scott N, Sheridan M and Toogood GJ: Xanthogranulomatous cholecystitis: a European and global perspective. HPB (Oxford) 16(5): 448-458, 2014. PMID: 23991684. DOI: 10.1111/hpb.12152

4 Deng YL, Cheng NS, Zhang SJ, Ma WJ, Shrestha A, Li FY, Xu FL and Zhao LS: Xanthogranulomatous cholecystitis mimicking gallbladder carcinoma: An analysis of 42 cases. World J Gastroenterol 21(44): 12653-12659, 2015. PMID: 26640342. DOI: $10.3748 /$ wjg.v21.i44.12653

5 Yeh BM, Nobrega KT, Reddy GP and Qayyum A: Juvenile xanthogranuloma of the heart and liver: MRI, sonographic, and CT appearance. AJR Am J Roentgenol 189(4): W202-204, 2007. PMID: 17885031. DOI: 10.2214/AJR.05.1398

6 Cheng M and Cheung MT: Xanthogranuloma of liver: experience of a specialist surgical unit. ANZ J Surg 82(9): 663-665, 2012. PMID: 22943093. DOI: 10.1111/j.1445-2197.2012.06163.x

7 Vogt DP, Henderson JM and Chmielewski E: Cystadenoma and cystadenocarcinoma of the liver: a single center experience. $\mathrm{J}$ Am Coll Surg 200(5): 727-733, 2005. PMID: 15848365. DOI: 10.1016/j.jamcollsurg.2005.01.005

8 Fukunaga $\mathrm{N}$, Ishikawa $\mathrm{M}$, Ishikura $\mathrm{H}$, Ichimori $\mathrm{T}$, Kimura $\mathrm{S}$, Sakata A, Sato K, Nagata J and Fujii Y: Hepatobiliary cystadenoma exhibiting morphologic changes from simple hepatic cyst shown by 11-year follow up imagings. World J Surg Oncol 6: 129, 2008. PMID: 19077232. DOI: 10.1186/1477-7819-6-129

9 Nguyen BD: Hepatobiliary and Pancreatic: Hepatic necrobiotic xanthogranuloma. J Gastroenterol Hepatol 32(10): 1667, 2017. PMID: 28948701. DOI: 10.1111/jgh.13858

10 Nishida Y, Kobayashi E, Kubota D, Setsu N, Ogura K, Tanzawa Y, Nakatani F, Kato Y, Chuman $\mathrm{H}$ and Kawai A: Chronic expanding hematoma with a significantly high fluorodeoxyglucose uptake on ${ }^{18} \mathrm{~F}$-fluorodeoxyglucose positron emission tomography, mimicking a malignant soft tissue tumor: a case report. J Med Case Rep 8: 349. PMID: 25335527. DOI: 10.1186/1752-1947-8-349
11 Ishak KG, Willis GW, Cummins SD and Bullock AA: Biliary cystadenoma and cystadenocarcinoma: report of 14 cases and review of the literature. Cancer 39(1): 322-338, 1977. PMID: 318915. DOI: $10.1002 / 1097-0142(197701) 39: 1<322::$ aidcncr2820390149>3.0.co;2-p

12 Thomas KT, Welch D, Trueblood A, Sulur P, Wise P, Gorden DL, Chari RS, Wright JK, Washington $\mathrm{K}$ and Pinson CW: Effective treatment of biliary cystadenoma. Ann Surg 241(5): 769-773, 2005. PMID: 15849512. DOI: 10.1097/01.sla. $0000161982.57360 .1 \mathrm{~b}$

13 Bakoyiannis A, Delis S, Triantopoulou C and Dervenis C: Rare cystic liver lesions: a diagnostic and managing challenge. World J Gastroenterol 19(43): 7603-7619, 2013. PMID: 24282350. DOI: $10.3748 /$ wjg.v19.i43.7603

14 Beppu T, Wakabayashi G, Hasegawa K, Gotohda N, Mizuguchi T, Takahashi Y, Hirokawa F, Taniai N, Watanabe M, Katou M, Nagano H, Honda G, Baba H, Kokudo N, Konishi M, Hirata K, Yamamoto M, Uchiyama K, Uchida E, Kusachi S, Kubota K, Mori M, Takahashi K, Kikuchi K, Miyata H, Takahara T, Nakamura M, Kaneko H, Yamaue H, Miyazaki M and Takada T: Long-term and perioperative outcomes of laparoscopic versus open liver resection for colorectal liver metastases with propensity score matching: a multi-institutional Japanese study. J Hepatobiliary Pancreat Sci 22(10): 711-720, 2015. PMID: 25902703. DOI: $10.1002 /$ jhbp.261

15 Beppu T and Yamamoto M: Laparoscopic versus open liver resection for colorectal liver metastases-which is a more suitable standard practice? Ann Surg 267(2): 208-209, 2018. PMID: 29064901. DOI: $10.1097 /$ SLA.0000000000002550

16 Someren A: "Inflammatory pseudotumor" of liver with occlusive phlebitis. Report of a case in a child and review of the literature. Am J Clin Pathol 69(2): 176-181, 1978. PMID: 629225. DOI: 10.1093/ajcp/69.2.176

17 Nakajima T, Sugano I, Matsuzaki O, Nagao K, Kondo Y, Miyazaki M, Konno A and Shimura T: Hepatic inflammatory lesions manifested as a pseudotumor. Report of two cases with different characteristics. Arch Pathol Lab Med 117(2): 157-159, 1993. PMID: 8427563.

18 Kawashita Y, Kamohara Y, Furui J, Fujita F, Miyamoto S, Takatsuki M, Abe K, Hayashi T, Ohno Y and Kanematsu T: Destructive granuloma derived from a liver cyst: a case report. World J Gastroenterol 12(11): 1798-1801, 2006. PMID: 16586558. DOI: $10.3748 /$ wjg.v12.i11.1798 